\title{
Solution of Problems of Development of the Electronic Government in the Republic of Kazakhstan
}

\author{
Turtubek Umutkanovich Sadykov ${ }^{1} \&$ Azamat Aytbayevich Taizhanov ${ }^{1}$ \\ ${ }^{1}$ L. N. Gumilyov Eurasian National University, Astana, Munaytpasov Street, 5, Republic of Kazakhstan \\ Correspondence: Turtubek Umutkanovich Sadykov, L. N. Gumilyov Eurasian National University, 100008, \\ Astana, Munaytpasov Street, 5, Russian Federation. E-mail: azamat.ap@mail.ru
}

Received: August 19, 2014 Accepted: August 27, 2014 Online Published: November 27, 2014

doi:10.5539/ass.v10n24p134 URL: http://dx.doi.org/10.5539/ass.v10n24p134

\begin{abstract}
In this work the questions connected with the solution of problems of development of the electronic government in Kazakhstan are considered. Character of such problems and a way of their solution are presented. The review of a number of the major features and the moments which reflect the main directions of electronization and informatization in Kazakhstan is executed. The short analysis of the main tendencies in development of the electronic government in Kazakhstan is made. The comparative characteristic of development of the electronic government is internationally provided in Kazakhstan.
\end{abstract}

Keywords: electronic government, infrastructure of the electronic government, informatization of government bodies, systems of public administration, electronic and digital signature

\section{Introduction}

According to the State Program "Information Kazakhstan-2020", approved by the Decree of the President of the Republic of Kazakhstan as of January 8, 2013 \#464 "On the State Program "Information Kazakhstan-2020" and amending the Decree of the President of the Republic of Kazakhstan as of March 19, 2010 \#957 "On approval of the List of state programs", by 2020 the electronic government index (according to UN) should be among the first 25 countries of the world (1:4).

The Resolution of the Government of the Republic of Kazakhstan as of April 20, 2012 \#505 "On amending the Resolution of the Government of the Republic of Kazakhstan as of February 11, 2011 \#129 "On the Strategic Plan of the Ministry of transport and communications of the Republic of Kazakhstan for the period of 2011-2015" reflects the following basic problems hindering the development of the electronic government of the Republic of Kazakhstan:

1) low level of security of information and communication networks, information systems and resources of government bodies;

2) slow pace of the automatization of business processes of government bodies aimed at providing public services in electronic form;

3) insufficient provision of public services in electronic form on the principle of "one window" (2:3).

The IT industry is one of the fastest growing industries in the world. The growth of this industry is based upon expansion of the general penetration of IT-technologies into the business processes of organizations, governance mechanisms and people's daily lives.

The main tendencies of the industry development include the gradual decrease in the proportion of the equipment cost in the total IT market, outstripping the growth of services in relation to the segment of the software.

The intensive introduction of modern information technologies in the economy, public administration, as well as a variety of social processes, is an essential component of the accelerated development of the Republic of Kazakhstan, the structural changes in the economy (3: 43).

The modern development of human civilization is characterized by the next stage of the scientific and technological revolution-the implementation in all aspects of information and communication technologies (hereinafter-ICT) which change the people`s lifestyle and form the foundation and the material basis for the 
transition to the information society, the society with a high socio-economic, political and cultural development. In the world there widely observed the following tendencies:

1) transformation of all public institutions and spheres of human activity under the ICT influence;

2) progress in all areas of development, production and implementation of modern technologies;

3) commitment to developing the advanced information environment adequate to the tasks of socio-economic development of the country;

4) ensuring an equal guaranteed access to the information resources;

5) preparation of citizens, public institutions, businesses and public authorities at all levels for the life in the information society.

\section{Methods}

In most advanced countries, such as Canada, Korea, Malaysia, Singapore, the United States of America, developed and implemented the strategies or integrated programs of information development of the society as a whole and its separate spheres of activities.

\subsection{Methods for Analysis and Synthesis}

Analysis and synthesis of the above strategies and programs show that the leading role in the formation of the national strategy for the information development, consolidation of all social classes for achievement the goals related to information and innovative development, coordination of business, all public institutions and citizens for implementation of the national strategy is given to the State.

In the Republic of Kazakhstan the main emphasis has been made only on one of the components of the information society-on the formation and development of electronic services that are being successfully implemented, as evidenced by the top international ratings. However, the task of formation of the information society is certainly broader than the development of electronic services and telecommunications (4:2).

Based on the international experience of establishing the information society and the provisions of the above-mentioned documents, the program on the society informatization has determined four key directions:

- provision of the effectiveness of the system of the electronic government and public administration;

- provision of the accessibility to the ICT infrastructure;

- improvement of the quality and conditions of life through the ICT introduction;

- development of the national information space.

In the Republic of Kazakhstan within the framework of these directions through the widespread ICT introduction the problems of improvement of public administration and development of accessibility to the information infrastructure shall be solved (5:3). Considering the fact that the development of the information society must be accompanied by the development of human resources, the program on the informatization of the country provides the conditions for creating opportunities for citizens to learn and acquire the skills of working with information technologies through e-learning, lifelong learning and training, work remotely, use services of the available eHealth. With the purpose of establishing more open, accessible and competitive economy of the Republic of Kazakhstan it is also provided the maximum implementation of intelligent systems into the basic sectors of the economy (3: 83).

\subsection{Methods for Monitoring of the Official Websites of Public Authorities}

In the ranking of the United Nations E-Government Survey-2012 "Electronic government for people", published at the beginning of March 2012, Kazakhstan was ranked 38th gaining 8 more positions in comparison with 2010. Such rankings are based on the methods for monitoring of the official websites of public authorities. Indexes used in the UN Global E-Government Readiness Report assess the countries` readiness for development of the electronic government (e-Government Readiness) and electronic participation (e-Participation). The following two aspects influence the development of the electronic government:

- opportunity or capacity of the public sector for deployment of the ICT infrastructure that allows to improve the quality of services provided for individuals and businesses, that is the country's readiness for creation of the electronic government;

- readiness (willingness), which means the measures taken by the government, aimed at providing information and knowledge for improvement of the satisfaction degree of the population. The UN has published its annual 
review of the electronic governments in the world-E-Government Survey 2012. 190 countries participated in the study.

All countries of the world are combined into the E-government development index, EGDI. 190 index positions are formed on the basis of 3 indicators:

- online services;

- telecommunications infrastructure;

- human capital assets.

The main eGov-tendency was confirmed in 2012: countries with high economic development began to actively use the electronic government (6: Table 1). South Korea expectedly charts Top-20 world leaders in the development of the electronic government. It is followed by the leading European economies-the Netherlands, the United Kingdom, Denmark, and the United States are ranked the fifth among the top leaders. Israel, Luxembourg and Liechtenstein are placed on the top of 2012 among new countries. Their rankings got ahead of the recognized eGov-leaders-Japan and Estonia. However, the latter consistently rounds out of the Top-20. In 2010 this Baltic Republic had the same result.

Table 1. World e-government development leaders 2012 (6)

\begin{tabular}{lll}
\hline Rank & Country & E-government development index \\
\hline 1 & Republic of Korea & 0,9283 \\
2 & Netherlands & 0,9125 \\
3 & United Kingdom & 0,8960 \\
4 & Denmark & 0,8889 \\
5 & United States & 0,8687 \\
6 & France & 0,8635 \\
7 & Sweden & 0,8599 \\
8 & Norway & 0,8593 \\
9 & Finland & 0,8505 \\
10 & Singapore & 0,8474 \\
11 & Canada & 0,8430 \\
12 & Australia & 0,8390 \\
13 & New Zealand & 0,8381 \\
14 & Liechtenstein & 0,8264 \\
15 & Switzerland & 0,8134 \\
16 & Israel & 0,8100 \\
17 & Germany & 0,8079 \\
18 & Japan & 0,8019 \\
19 & Luxembourg & 0,8014 \\
20 & Estonia & 0,7987 \\
\hline
\end{tabular}

However, the differences between the leaders are insignificant, since within the last two years all of these countries actively invested in the national eGov-technologies almost on the same model. The main criterion for development of online services of electronic governments has become the one-stop-shop portal or the "one window" portal.

Leader-2012-the portal of the electronic government of South Korea-won the first place due to the numerous mobile applications for iPhone and Android devices and complete coverage of the country with 3G-Internet. The portal has collected at one point $87 \%$ of all national and local services-that was the best world result. Each citizen can set up the South Korean electronic government for his/her own personal needs and have a continuous access to it through mobile applications. Significantly, e-Gov in South Korea includes a complete e-learning system and online labor exchange.

The Netherlands took the second place due to their system of the close communication of state agencies used for 
ensuring the maximum comfort for clients-an electronic "single window". The Netherlands successfully implemented an e-ID for citizens and enterprises. The high level of the broadband access network, according to UN experts, will help the Netherlands to successfully develop the national electronic government.

The countries of the Northern Europe have the best results among the other world regions, 6 out of 10 countries are at the top of the E-GDI list. Obvious improvement of the user interface and operation of the Direct Gov portal, as a single point of all government information and services, provided the UK the high 4-th level of the index. Separately noticed "Do It Online" pages which lists all public services, forms, tools and operations provided by the government, and electronic service of the job search Jobcentre Plus.

E-Gov portal of the Denmark is the center of electronic transactions across the country, connecting the state, entrepreneurs and the population into the same network. Electronic invoices annually save 150 million Euros of the citizens and 50 million Euros of the business. Every Dane has a personal E-Box e-mail, which collects emails from all government agencies and companies of the Kingdom. Among the services of the portal of the Danish government there are student loans, the state pension management, the possibility of recording the income and marital status.

Usa.gov is marked as a state portal with a high degree of integration of all the elements. Detailed information allows American citizens to easily find the desired e-service at the national or local levels. The availability of reference, search, internal taxonomy, a variety of methods of communication with the government authorities and access to numerous databases of public data make Usa.gov one of the model e-Gov sites in the world. The Canadian Government has the similar portal. Being pioneers in the development of electronic government, these countries of North America confidently occupy the top positions of the EGDI index since 2003.

Singapore is a constant leader among the Asian countries. In Singapore they continue to develop cloud technologies, such as a cloud created for communication between teachers. The portal for Singapore citizens provides the maximum range of online-payments: from taxes and fees to licenses and fines.

E-participation index is an indicator of the development of services for active communication between citizens and the state or the Gov 2.0 index. In this regard, in Kazakhstan there are many online services for direct communication between the citizens and the highest officials, the blog of the government of Kazakhstan with commenting, visual statistics of public employees` responses and citizens` questions that, taken together, is positively marked by UN experts.

\section{Research Results}

\subsection{The Research Results Aimed at Improving the Quality of E-Services}

The results show that increasing the number of public services, provided in electronic format, make it necessary to inform the users of the E-services portal of the existing and planned public services. So that the user is not offered the services which he/she is not interested in, an individual approach should be applied. For instance, if the user has the ID, which contains the information about the expiry date of such document, the portal should and can timely inform the user about the need to replace the ID and perform such an operation through the relevant service.

The obtained results of the scientific analysis suggest that the vector of development of the electronic government in the Republic of Kazakhstan should be shifted towards improving the quality of services provided. According to our calculations, it is expected that the number of users by the end of 2019 will reach 1087 thousand while the number of transactions carried out by the registered users and stored documents by 2016 will increase to 12,206,179,440 (for comparison: at the beginning of 2014 this number was 6,352,482,240).

The State Program "Information Kazakhstan-2020" states that the infrastructure of the electronic government helps to solve the problem of providing the necessary information for citizens, businesses and government agencies, there conducted an annual evaluation of the activities of government bodies on the application of information technologies and provision of the electronic public services (1: 14).

In this regard, according to the results of our research in order to solve the problems of the electronic government in Kazakhstan and improve the quality of services provided it is necessary to carry out the following activities:

1) through the optimization of the system to complete the computerization of public administration;

2) to achieve transparency of government bodies;

3) to introduce new modern models of the informatization of government bodies. 
The driving force behind many administrative reforms should be widespread government use of infrastructure of the electronic government. For a full solution of the above-mentioned problems it is necessary to accelerate the development of the "open government" portal, which also consolidates the data for planning and actual development of the budget by the government bodies.

In such conditions occurs the increased involvement of citizens, public associations of local governments, non-governmental organizations into the process of constant public monitoring of the quality of public services. There formed social sites on the Internet for public discussion of the social problems between public agencies and the population, as well as created and launched a mechanism for involving citizens into the process of reforming and improving the performance of the state. Mechanisms for citizens` electronic evaluation of the effectiveness of the government bodies are being implemented, including the management of all levels and local authorities.

\subsection{The Research Results Aimed at Creating the Harmonious Development Scheme of the Electronic Government in General}

During the research we have conducted a scientific analysis of the various new subsystems of the electronic government of the Republic of Kazakhstan. The research results can be presented by the following main points and conclusions, namely: implemented at different time the subsystems of the electronic government of the Republic of Kazakhstan should be combined into one circuit and added with a number of new subsystems, the implementation of which will allow to create a harmonious development scheme of the electronic government in general.

Thus, solution of the problems of development of the electronic government in Kazakhstan is interconnected with the transformation of its existing subsystems and modules into a single and coherent system. The following subsystems of the electronic government in Kazakhstan are subject to the transformation and change: E-government portal, E-government gateway, E-government payment gateway, Public access stations, as well as new subsystems as: E-government exterior gateway, Storage of the electronic documents and Unified reference data. All of these subsystems are an integral part of a single loop of the web portal and "electronic government" gateway.

In particular, the E-government portal will not be able to fully implement public services without the software and hardware of the E-government payment gateway. This gateway is necessary for arranging the integration with the second-tier banks. The E-government exterior gateway is necessary for arranging the integration with subsystems, which do not have an access to the E-government gateway, in particular, when integrated with the workflow systems of commercial organizations.

The Storage of electronic documents will provide the relevant information for the e-services portal, information systems, public service centers and licensed unified trust centers. Filling them with electronic scanned copies and forms of documents makes it possible to reduce the requirements for users, reduce paper work and ensure the provision of the services on the E-government portal by using paperless document circulation.

The Unified reference data is intended not only to provide the entire system of the web-portal and gateway of the "electronic government" with the unified reference data, but also to satisfy all information systems with the necessary information through a single point of access to the unified reference data in the entire state. Such an approach will allow all entities to avoid errors in the information system in registration of the reference data, thereby provide the accuracy, completeness, timeliness of the information transfer and eliminate unnecessary duplication at its receiving.

In terms of the unified and comprehensive system the E-government portal will represent a unified resource where there is a real online opportunity for timely receipt of services by the government bodies, as well as the payment of taxes and fines. In addition, this Portal is considered to have comprehensive official information about Kazakhstan, its government, law and national attractions.

In most cases, obtaining services of the electronic government requires an electronic and digital signature (EDS) (9: 8). In accordance with the data about the quantity of the issued electronic and digital signatures, published on the official website of the National Certification Centre of the Republic of Kazakhstan (pki.gov.kz) as of July 1, 2011, the entire number of issued EDS is 2,346,372; including (7):

- in 2008: 2,340 EDS,

- in2009: 105,300 EDS,

- in 2010: $316,000 \mathrm{EDS}$, 
- in 2011: 478,292 EDS,

- in 2012: 455,720 EDS,

- in the first half of 2013: 988,720 EDS.

Thus, analyzing the statistics on the electronic and digital signatures issued from 2011 to the 1st half of 2013 inclusive, it may be concluded that there is a tendency of increasing demand for electronic and digital signatures by an average number of 354,086 EDS per year, representing $50 \%$ of the average number of the issued electronic and digital signatures per year. Consequently, by the end of 2016 the number of the issued electronic and digital signatures could reach 2,050,978.

\section{Discussion}

\subsection{Discussion of the Problem of the Effective Reference Data Management}

According to the research results solution of problems of development of electronic government in Kazakhstan requires discussion of such a complex issue as the effective reference data management, its documentation and information safety. Currently $70 \%$ of major commercial companies in the country have already automated their business processes in terms of reference data management. However, depending on the scale of an organization, the number of automated information systems on reference data may reach several tens (8: 12). All existing systems generally use their reference data, which is stored in different information references (14:6). The results of such obsolete approach to the reference data management are as follows:

1) difficulty of formation of consolidated statements within the entire organization;

2) financial losses due to the problems of operational control and analysis of industrial processes, as well as the absence of the possibility to timely correct the actions;

3 ) increased costs on maintaining local information systems and provision of information joining-the interface between different systems.

To solve these problems it is necessary to develop such approaches allowing all systems "to speak the same language", that is to create a unified system of classification and codification information or a unified system of reference data management (15: 7). This development will be one of the most important elements of creating a unified information space. Then, in all organizations and their areas of activities in Kazakhstan, regardless of where they are situated, there will be used unified names of objects, while the operation of different information systems will be based on the general regulations, rules and proceedings (16: 9).

The accession of the Republic of Kazakhstan to the Customs Union (Russia, Kazakhstan and Belarus) currently must take into account a significant number of difficult integration processes, so the using a unified electronic reference data in the operation of information systems is an essential requirement for the reliability and quality of rendered services (19: 2). Within the framework of electronic government of the Customs Union in the implementation of the information systems the delay of implementation of a unified reference data significantly increases the risks, that is:

1) Risk of the delay of implementation of the unified reference data due to prolonged administrative agreement of regulations of integrative interaction;

2) Risk of rise in the cost of implementation of the unified reference data due to the need for realization of different integration modules with their original sources;

3) Risk of receiving soft data due to the use of non-actual information about the reference data.

According to our calculations the minimum number of requests on the E-government portal may increase to 335,530 per minute by the end of 2016 in Kazakhstan, due to the technical and technological opportunities created by the unified reference data. In general, implementation of the unified reference data will allow a comprehensive automation of administrative procedures and business processes. This implementation will allow to receive and provide the public, business, government and other government bodies different kinds of services through the creation of unified centralized information space of the reference data management (17: 9).

According to our forecasts in 2015 the Public Service Centers in Kazakhstan will provide the population with 572 public services or $76.8 \%$ of their total (745) services of the required list of services. At that, automation of each public service will require the creation of an electronic form of the application (11: 3). Whereas the task of automation the issuance of enabling documentation is a part of the common task of automation of public services, the long-range demand on downloadable interactive electronic forms can reach 572 standard forms in the period of 2015-2016. 


\subsection{Discussion of the Problem of Electronic Documentation}

One of the problems of development of electronic government in Kazakhstan is the problem of the formation of form templates and prepared documents for sending to the storage in the integrated information system of service centers (12: 8). With the objective of ensuring information safety, this problem should be solved at the level of electronic government gateways.

The solution of this problem will allow not only to provide the information safety, but also to work off the mechanisms guaranteed sending-delivery of electronic documents for storage and reutilization (13: 7). The task called "Development of the web-portal and E-government gateway of the Republic of Kazakhstan" sets a goal of the realization of possibility to unify and enter 20 new templates of electronic forms used for creation electronic documents in order to enhance the level of information safety.

Taking into account the world experience on the arrangement of the direct dialogue between the population and the state, it is necessary to aspire to the interaction between the government bodies and citizens under confidentiality agreements. This task includes a set of modules and subsystems oriented to achieving the provision of the direct dialogue between the state and the citizen: the module for discussions of laws and bills, as well as the module "Open government". All this, taken together, will allow to achieve transparency of activity of government bodies, as the possibility emerges to the users of the electronic government portal to express their opinion and to get quick answers and explanations in the form of electronic documents from the same government bodies.

Additionally, in Kazakhstan through the system of electronic documents Public access points also allow citizens to easily contact to the E-government portal and get any public service (18: 9). Public access points were established to ensure equitable access to the state and other information resources, eliminate the information inequality between megacities and residents of the rural areas and small towns, improve computer and general literacy through the use of the Internet technologies (20: 18).

But, however, currently there is occurs a problem that only two public services can be rendered on Public access points. Thus in 2016 perspective it will be necessary to include at least 9 (nine) additional public services rendered to the population through the Public access points.

4.3. Discussion of the problem of information safety. In accordance with Paragraph 3 of Article 17 of the Law of the Republic of Kazakhstan "On Informatization as of January 11, 2007 \#217", "Testing of software products, software codes and conducting an expertise of normative-technical documentation" shall be carried out (8: 29). Additionally, according to the Resolution of the government of the Republic of Kazakhstan of December 30, 2009 \#2280 "On approval of the Rules for certification of the state information systems and non-state information systems, integrating with the state information systems, for their compliance with requirements for information security and standards approved on the territory of the Republic of Kazakhstan", it shall be necessary to conduct the certification of the information systems (10:7).

In this regard the conducted analysis of public services and certification of the information systems of government bodies for their compliance with the requirements of modern software products, as well as the necessary information safety, has lead us to the following basic problems and their solution (21: 11).

The basic problems are:

- the majority of application systems used in information networks are built on different hardware and software platforms;

- application systems are insufficiently integrated with each other, they use the references not completely standardized or different in structure and composition;

- insufficient centralized system of support of the user access to the reference data;

- insufficient application system on the changes of the reference data;

- insufficient notification system of subscribers about the change of values of the reference data;

- the existing references do not fully describe the accounting objects, the names of these objects are insufficiently unified and the coding system is insufficiently standardized.

Additionally, it should be emphasized that the provider of public services is the Republican state enterprise on the rights of economic management "State technical service" of the Ministry of transport and communications of the Republic of Kazakhstan. Therefore, for such technical services it should be mentioned the following major ways of solving problems of improving software quality and effective provision of information safety: 
1) the need of check of the general structure for its compliance with safety policy and the order of components in the structure;

2) the need of check of the components configuration, which the information systems are composed of;

3) examination of organizational information security measures operated by the information system;

4) instrumental examination of information system components that allow the users to gain an access to the information, bypassing the existing protection mechanisms;

5) improving the quality of national products in the informatization and the exclusion of defects of software products in their implementation into production operations.

For the system of protection from unauthorized access to information, we suggest that the web-portal and the gateway of electronic government of Kazakhstan could effectively provide the following:

- protection from interference into the operation of the information systems by unauthorized persons;

- ensuring the identification and authentication of the users, involved in the process of information exchange through information systems;

- separation of the user access to resources of information systems;

- the determination of user rights to entry, adjustment, view of the data and access to the system resources based on a "role" model;

- logging of users actions on the web-portal;

- transfer and storage of password information exclusively in the encrypted form;

- monitoring the integrity of the component parts of information systems;

- protection from unauthorized modification;

- protection of confidential data from leaking through technical channels;

- protection of confidential information from unauthorized access or modification during processing, transmission or storage;

- the inability to avoid services, providing information security;

- the antivirus software must be installed on the workplace of each system user;

- regular procedures of backing-up, formation of the test and data copies and their timely reissuance must be installed;

- proprietary regulations and management of the organization for information security must be developed and agreed.

As a basic means of protection against unauthorized access it should be used the administration means of the operating system, data base management system and inter-network screens (firewall). Firewalls should at least provide the exclusion of the unauthorized access to protected network resources of the information system or be integrated into the system of information protection, as well as to support the flexible configuration of the proprietary safety settings and provide the maintenance, collecting and analysis of event logs.

The system of protection from unauthorized access to information should be changed according to implementation of new technologies and subsystems with regard to the requirements for information safety. In case of loss of the information system efficiency due to breakdown, errors or failures of software and hardware tools, the information system shall provide the safety of information accumulated until failure.

\section{Summary}

Thus, within the framework of tasks and solution of problems of development of the electronic government in the Republic of Kazakhstan we propose to use the following options:

1) On the basis of the analysis of functions and services of government bodies it is necessary to define a list of typical information systems. Typical information systems should be implemented into government bodies under the new informatization model in the form of "cloud services".

2) It is necessary to continue the process of reducing and simplifying business processes on the provision of the automated public services.

3) It should further automate the functions of local executive bodies with regard to the software interface and "cloud services". 
4) It is necessary to fully implement the Unified system of numbering and coding of administrative documents.

5) The comprehensive creation and implementation of the unified window of the interaction with the state will be required. Such window is intended for official information interaction of individuals and legal entities with government bodies and organizations in the provision of public and private services.

6) It should speed up the works on developing of infrastructure recording of the electronic and digital signature onto the IDs of a new sample aimed at large-scale use of such a signature by the population.

7) It will be necessary to increase the number of stations of the public access to electronic services, as well as upgrade the equipment of existing subscriber stations.

The implementation of the proposed options, all taken together, will allow the Republic of Kazakhstan to have a number of socio-economic benefits. Socio-economic benefits of solving the problems of electronic government for citizens and businesses in Kazakhstan are as follows:

8) reduction of time used for receiving services by improving the efficiency of electronic processes;

9) empowerment of interaction and integration with commercial organizations that improve the provision of electronic certificates, payment documents and other services;

1) establishment of the direct access and interaction between information systems of commercial organizations and national companies through E-government gateways.

Socio-economic benefits from solution of problems of development of the electronic government for the government bodies of Kazakhstan will be as follows:

2) reduction of time used for the business processes management, presented in the framework of integration with the E-government portal;

3) formation of a unified standard of e-mail numbering, reduction of the time used for search of the document type and the government body when working with electronic documents;

4) availability of reference data for any agency of the government body, company, organization in real-time, regardless of their location;

5) clear allocation of responsibility for the management of the specific directories and unified reference data;

6) stable operation of services of the E-government portal through monitoring and tracking of the configurations of services and their elements;

7) the unified system of numbering and coding of administrative documents and the use of automated systems for the processing and routing of documents simplify the search documentation.

In the meantime, for future reference it must be emphasized that in the future in accordance with the transition to alternative authentication mechanisms, namely, to the login/password and one-time passwords, some e-mail services will be provided to the users of the web-portal and E-government gateway without the electronic and digital signature. However, this situation will logically require the conduct of another and further scientific analysis.

Thus, in this work the results of studying current problems of electronic government in Kazakhstan and analysis of the experience of leading countries in the field of electronization and informatization indicate the readiness of the Republic of Kazakhstan to implement large-scale and complex public strategies of the information development and formation of the modern electronic government.

\section{References}

Council Decision \#54 "On approval of the single commodity nomenclature of foreign economic activity of the Customs Union and the Common Customs tariff of the Customs Union". (2012, July 16). Eurasian Economic Commission. Moscow.

E-government development index. EGDI.

Joint Decree drawn up by the Chairman of the Agency for Information and Communication of the Republic of Kazakhstan as of June 29, 2007 \#287-r and the Minister of Justice of the Republic of Kazakhstan as of June 29, 2007 \#193 "On approval of the Rules for certification of legal identity of a paper copy of an electronic document having legal force, conducted by the Public Service Centers". (2007, July 20). Registered in the Ministry of justice of the Republic of Kazakhstan \#4820.

Official website of the National Certification Centre of the Republic of Kazakhstan. (n. d.). National 
Certification Authority. Retrieved August 29, 2014, from http://www.pki.gov.kz/index.php/en/

Sadykov, T. (2010). Methodology of information economy: The scientific monograph. Lomonosov Moscow State University. Moscow: TASIS.

The Decree of the President of the Republic of Kazakhstan \#573 "The State Program for formation and development of the national information infrastructure of the Republic of Kazakhstan". (2001, March 16). "Kazakhstan Today" as of March 20, 2001 \#73; SAPP of the Republic of Kazakhstan, 2001, No. 10, Art. 108.

The Law of the Republic of Kazakhstan "On Electronic Document and Electronic Digital Signature" \#370-II. (2003, January 7).

The Law of the Republic of Kazakhstan "On Informatization" \#217-III. (2007, January 11).

The method of application of indicators defining the computer literacy of the population. (2008, March 11). Approved by the Order of the Chairman of the Agency for Information and Communication of the Republic of Kazakhstan \#76/1.

The methodology for evaluation of the readiness of regions of the Republic of Kazakhstan for the information society. (2008, March 5). Approved by Order of the Chairman of the Agency for Information and Communication of the Republic of Kazakhstan \#68/1.

The model standard for the provision of public services. (2007, June 30). Approved by the Resolution of the Government of the Republic of Kazakhstan \#558.

The Program for development of information and communication technologies in the Republic of Kazakhstan for the period of 2010-2014. (2010, September 29). Approved by the Resolution of the Government of the Republic of Kazakhstan \#983.

The program of e-government development of the Republic of Kazakhstan for the period of 2008-2010. (2007, November 30). Approved by the Decree of the Government of the Republic of Kazakhstan \#1155-1. Legal reference system "Lawyer". Retrieved October 9, 2008.

The Resolution of the Government of the Republic of Kazakhstan \#1 "On establishment of state institutions of public service centers of the Ministry of justice of the Republic of Kazakhstan". (2007, January 5).

The Resolution of the Government of the Republic of Kazakhstan \#2280 "On approval of the Rules for certification of the state information systems and non-state information systems, integrating with the state information systems, for their compliance with requirements for information security and standards approved on the territory of the Republic of Kazakhstan". (2009, December 30).

The Resolution of the Government of the Republic of Kazakhstan \#505 "On amending the Resolution of the Government of the Republic of Kazakhstan as of February 11, 2011 \#129 "On the Strategic Plan of the Ministry of transport and communications of the Republic of Kazakhstan for the period of 2011-2015". (2012, April 20). Astana.

The Resolution of the Government of the Republic of Kazakhstan as of June 30, 2007 \#558 "On approval of the model standard for the provision of public services". (2007, July 7). Kazakhstanskaya Pravda.

The Resolution of the Government of the Republic of Kazakhstan as of June 30, 2007 \#559 "On approval of model regulations for the provision of public services". (2007, July 10,). Kazakhstanskaya Pravda.

The Resolution of the Government of the Republic of Kazakhstan as of June 30, 2007 \#561 "On approval of the register of public services provided for individuals and legal entities". (2007, July 12). Kazakhstan Today.

The State Program \#464 "Information Kazakhstan-2020". (2013). Astana.

The state standard of the Republic of Kazakhstan ST RK 1.13-2005 "Standardization of public services. Basic requirements". (2005, December 29). Approved and put into effect by the Order of the Committee for Technical Regulation and Metrology of the Ministry of Industry and Trade of the Republic of Kazakhstan $\# 501$.

\section{Copyrights}

Copyright for this article is retained by the author(s), with first publication rights granted to the journal.

This is an open-access article distributed under the terms and conditions of the Creative Commons Attribution license (http://creativecommons.org/licenses/by/3.0/). 